\title{
Do Declining Neighborhood Economic Conditions Trump Hoped for School Renovation Renewal Benefit?
}

\author{
Carolyn L. Grice ${ }^{1}$, John W. Hill ${ }^{2}$, Karen L. Hayes ${ }^{2}$ \\ ${ }^{1}$ Omaha Public Schools, Omaha, USA \\ ${ }^{2}$ University of Nebraska at Omaha, Omaha, USA \\ Email: Carolyn.Grice@ops.org, \{jhill, karenhayes\}@unomaha.edu
}

Received March 24 $4^{\text {th }}$ 2012; revised April 22 ${ }^{\text {nd }}, 2$ 2012; accepted May $8^{\text {th }}, 2012$

\begin{abstract}
The purpose of this study was to determine 1) individual student achievement, 2) teacher mobility rates, 3) perceptions of safety at school, and 4) student enrollment patterns, over time, in two recently renovated, same city, urban, No Child Left Behind compliant, Title I elementary school buildings located in close proximity neighborhoods one with improving the other with declining economic conditions. Achievement results indicated that fifth-grade students $(n=18)$ who attended a renovated school second-grade through fifth-grade in a neighborhood with improving economic conditions compared to fifth-grade students $(n=$ 15) who attended a renovated school second-grade through fifth-grade in a neighborhood with declining economic conditions had statistically greater high stakes Reading Total and Math Total but not Language Total achievement test score improvement frequencies over time and statistically greater posttest-posttest Normal Curve Equivalent high stakes achievement test score comparisons for Reading Total, Math Total, and Language Total. Differing neighborhood economic conditions had no statistical effect on reported teacher, student, and parent perceptions of school safety or teacher mobility rates, however, enrollment in the renovated school in the neighborhood with declining economic conditions dropped significantly. We conclude that declining neighborhood economic conditions trumped hoped for school renovation renewal benefit. School closing policy and student open enrollment transfer options are discussed.
\end{abstract}

Keywords: School Renovation; Neighborhood Economics; Renewal Outcomes; Achievement

\section{Introduction}

During the past twenty-five years, an urban school district in the Midwest has spent 362 million dollars renovating the majority of its existing schools located within lower socioeconomic and impoverished neighborhoods of the city (Omaha Public Schools, 2004). The urban school district also recently constructed four completely new school buildings within these same areas. Within these renovated and newly constructed schools students learn (Kozol, 2005; Picus, Marion, Calvo, \& Glenn, 2005) and innovate (NEA 2004; Polakow \& Pettigrew, 2006) with parent participation (Bryan 2005; Epstein, Sanders, Simon, Salinas, Jansorn, \& Van Voorhis, 2002) and community support (Crew, 2007). However, almost overnight, several of these schools find themselves operating in neighborhoods of serious economic decline (Crowder \& Adelman, 2000; Crowley, 2003; Tolnay, Rankin \& Quane, 2000) and demolition of public housing (Jacob, 2004; Varady, Raffel, Sweeny, \& Denson, 2005). Because not all families can simply pick up and move to another neighborhood (Baskerville, 2008; Earls, 2000) to avoid these conditions, the students who remain in decreasing enrollment schools will typically be the most economically vulnerable (Anyon, Sadovinik, \& Semel, 2001; Nichols \& Gault, 2003), socially and emotionally fragile (Burke, 2002; Weisberg \& O’Brien, 2004), and educationally challenged (Taylor, 2005). Therefore, it is important that we evaluate and determine the impact of student learning in schools with increasing and decreasing enrollment patterns surrounded by economic improvement and decline and answer the question what is best for students: Should students stay in these schools or should students be reassigned to other schools by action of the school district administration?

\section{School Renovation and Construction}

Until recently, primarily from a lack of research, there was little evidence to indicate that the quality of a school facility impacted academic achievement (Picus et al., 2005). Most states do not collect data regarding the condition of facilities and student performance. Where facilities are in good condition, there are no indicators of linking those conditions to achievement (Jones, Brener, \& McManus, 2003). However, Reg Weaver, Past President of the National Education Association (NEA, 2004) recently wrote:

There are no excuses for schools where the textbooks and technology are as old as the parents of some of the children. In the richest country in the world, there is no excuse for millions of children attending public schools that are rundown. The physical condition of public schools is critical to student achievement and staff morale. Great public schools begin with modern facilities (p. 1).

According to the NEA, school construction and building upgrades are supported by the federal government through tax credits to bond holders instead of payments on interest that represents a major cost-saving incentive for taxpayers and school districts, across the nation, to improve and upgrade their school buildings. 


\section{Attendance}

The location of a school (McLean, 2003) and the distance from its population center can be a factor in attendance. Attendance patterns are also affected by parents' perceptions of safety even if transportation is provided (Hirsch, Lewis-Palmer, Sugai, \& Schnacker, 2004). Schools surrounded by economic decline are almost universally prejudged as being less safe than more economically viable neighborhoods (Haws \& Tennille, 2005; Storch, Krain, Kovacs, \& Barlas, 2002). Parents of younger children fear bullying by older children (Green, 2007; Hall, 2005) and parents of upper elementary age students fear the potential of their child being drawn into illegal and dangerous behavior, including drug and alcohol use, by older youth who themselves may have dropped out of school (Kinlock, Battejes, \& Gordon, 2004; Plybon \& Kliewer, 2001).

\section{Economic Decline}

Many neighborhoods have suffered economic decline over the past years (Rankin \& Quane, 2000). Inner city neighborhoods previously described as a mixture of poor working class families and middle class families are now considered disenfranchised with poor families concentrated in isolated urban settings. As neighborhoods decline economically the community experiences increased crime, increased teen pregnancy, and increased unemployment (Haley-Lock \& Shah, 2007). Neighborhoods in decline by definition are socially isolated. The consequence of social isolation carries over to the schools. Historically, African Americans migrated from the rural south to the industrialized north for three primary reasons: 1) higher wages, 2) greater job choice, and 3) better neighborhoods (Tolnay et al., 2000). Studies of neighborhoods that were previously white, and later became integrated, found that any successes achieved by African Americans moving there were short-lived since the neighborhood eventually reverted back to being segregated by race. Student mobility and academic achievement have been a source of concern for decades (Crowley, 2003).

Federal housing policy does not provide financial resources sufficient for the lowest income families to afford decent housing. Poorer families move more often than middle class families and the reasons for the moves are less than positive in many cases (Ainsworth, 2002). Stressors in family life that cause increased mobility patterns include unsafe housing contributing to poor health conditions, loss of a job, and nearby crime. Poor families spend more than $30 \%$ of their incomes for housing needs (Burkhauser \& Sabia, 2007) and often need to work two or three minimum wage jobs to afford even unsafe housing (Secombe, 2002). Research has shown a correlation between housing conditions and school performance (Nichols \& Gault, 2003). Social isolation thought of as the lack of contact or sustained interaction with individuals and institutions that represent mainstream society (Rankin \& Quane, 2000) has also been linked to living in poor inner city neighborhoods (Rankin \& Quane, 2000). Furthermore, data provided from the 2000 Census indicates that children who live in families with incomes in the lowest 20 percent live with only one parent, and nearly half move every year. Within this same demographic over 4 million children were reportedly living with grandparents, and onefourth of these grandparents have sole primary care responsibilities for the children. These statistics present several chal- lenges for schools in neighborhoods of poverty.

\section{Demolition of Public Housing}

In a comparative study analysis of the Hope VI Project in four urban communities, it was found that the goal of developing public housing for mixed income families was difficult to achieve (Varady et al., 2005). Only one of the four study sites intentionally collaborates with the school district and other government entities such as the city government and housing authority. The Hope VI Project was created to replace public housing that was beyond repair and replace it with less dense developments, thereby reducing concentrations of poverty through mixed income communities. The efforts in one of the communities resulted in creating a community magnet school. A study conducted in Chicago found that living in public housing was directly correlated with increased crime, economic and racial segregation, lower achievement in school, and fewer job opportunities for the residents (Varady, Raffel, Sweeney, \& Denson, 2005). These combine to lead to increases in mobility. Housing vouchers were offered to individuals to encourage them to find better and more affordable places to live, and when all families had relocated, the public housing was razed.

\section{Children Who Are Socially and Emotionally Fragile}

In the most challenging of school environments, teachers must remember they have an important role in the lives of their students (Burke, 2002). For students of poverty, the teacher plays an important social and emotional support role, second only to the mother and father. Teachers must comprehend the social and emotional needs of their students and view them as unique, complex beings. A fearful, frightened, hungry, or abused student has to have his/her emotional needs met before he/she can concentrate on the lesson of the day. Minority students succeed in schools where it has been determined that there are no acceptable excuses for failure and no reliance on a cultural deficit to prevent children from achieving-another way adults, especially the teacher, communicate love and caring (Towns, Cole-Henderson, \& Serpell, 2000). In a study of four schools across the country, factors utilized by school staffs to help students achieve included going beyond goals and exceeding expectations while developing trust among the students and their parents. Among the practices that aided this endeavor were: 1) accountability of families, 2) careful consideration in the process of selecting the teaching staff, 3) priority given to teaching basic skills, and 4) adequate resources. As successful learning takes place and children succeed in emotionally supportive classrooms they become stronger and less socially and emotionally fragile.

Life experiences such as increased economic and social family pressures, access to media, and weakening of social institutions like church have changed drastically since the late 20th Century (Weisburg \& O’Brien, 2004). Schools that serve high needs students lacking such social and emotional skills have a major challenge. Programs are being created to address social issues like public and mental health, or juvenile justice initiatives, but many are not directly linked to the challenges educators encounter and of which they have no control. Social and Emotional Learning (SEL), is defined as a conceptual framework addressing the needs of children and the fragmentation of school responses. SEL provides common language and a frame- 
work for communicating about family, school, and community programs that teach academic success, health, service, character, and citizenship, as well as social-emotional topics. Integrated SEL programs assist schools in coordinating efforts and programs to promote positive social, emotional, and academic growth of all students, especially those that are socially and emotionally fragile.

\section{Review of Literature}

The quality of a school is an important factor for people when deciding where to live. The role of choice, not only in the selection of a school but also in the selection of living in an economically viable part of town, has become a significant factor in school enrollment (Gordon \& Richardson, 2001). Property rights and values are determined by where one chooses as a place of residence. All families want to live in a neighborhood that is affordable with opportunities for upward mobility and the best possible educational programs for their children. However, affordable, quality housing for low-income renters and families is being eroded by the demolition of large public housing projects (Nichols \& Gault, 2003). Minimum wage employment, lack of affordable low-income housing, and few social support agencies often means that families facing poverty must move to even less desirable neighborhoods that are experiencing even greater economic decline with inferior and crumbling schools (Kozol, 2005).

\section{Urban Schools in Neighborhoods of Economic Decline}

While neighborhood redevelopment planning is ongoing, population decline in many urban neighborhoods has left school district officials and planners with no option other than to begin closing schools with rapidly decreasing student enrollments (Varady et al., 2005). Many parents, when they are able to and have the economic means, relocate from decreasing neighborhoods. Unfortunately, other parents with fewer economic options, out of necessity, must keep their children in schools that are deteriorating (Kozol, 1991; 2005; Meredith, 2003). These neighborhoods experience decreasing enrollment patterns in the schools that remain open and become what is referred to as transition neighborhoods (Crowley, 2003; Lawhon, 2003). An intervention such as housing vouchers for lowincome families offers the opportunity to move to a neighborhood that is stable with affordable housing. If the family does not have to move then the mobility rate of the neighborhood schools also remains stable. Studies clearly indicate that schools in these transition neighborhoods must work harder to reach out to parents to help them become engaged in the life of the school, stay involved, feel valued and appreciated in order to ensure student achievement and success in the midst of economic decline (Meredith, 2003).

Models exist that are thought to be viable means in developing neighborhood designs in an effort to contain urban sprawl (Lawhon, 2003). The impact of such designs determines the number of people that will move to the area, which has a direct correlation to the number of schools being built to accommodate the population. Wealthier citizens have the ability to move to the suburbs while many citizens, left in the core of an urban city, need more health care, have transportation issues, participate in welfare programs, and do not have the finances to pay for needed services (Meredith, 2003).

School closures and consolidations are inevitable because of decreasing birthrates and baby boomers growing older (McLean, 2003). School boards see these closures and consolidations as a way to save money. Opposition to school closures range from the school being the heart of the community, to needing more study before determining to close a school, as well as looking at the housing and business development occurring in the area (McLean, 2003). Parents with few economic options have little choice but to stay in schools with decreasing enrollments. Jobs or lack of jobs keep them in the area, as does minimal access to transportation.

Research indicates that schools in areas of economic decline 1) provide fewer learning options (Frankenberg \& Lee, 2002), 2) a less experienced teacher core (Breitborde, 2002; Gehrke, 2005), and 3) deteriorating facilities, all considered to be detrimental to the learning success of children. Unequal opportunities and outcomes are linked to concentrations of poverty, which are connected to segregation by race and poverty (Frankenberg \& Lee, 2002).

\section{Deteriorating Facilities}

It has become a necessity to close the gap in the quality of school facilities for the education of children (Arsen \& Davis, 2006). Eleven states have court decisions that mandated local districts to improve buildings attended by a disproportionate number of children from low-income families. Feasibility procedures, created to determine calculations for the cost of whether school facilities are negatively impacting academic achievement, include measuring the existing capital stock-such as school buildings and related infrastructure-and determining the cost of bringing existing school facilities up to an adequate standard (Argon, 2008). As school districts find ways to improve student achievement, the physical condition of the building plays a significant role (Argon, 2008). Many school districts nationwide are reacting to economic strains as they look at maintenance and operations budgets. Because of increases in costs of energy and utilities, funds are being taken from other areas resulting in a continued decrease in funds to maintain the facilities, thereby causing deterioration that is not being repaired. Even though costs are increasing, the most recent cost analysis indicates that maintenance and operation budgets have decreased to 8.35 percent, down from 9.19 percent from the previous year (Argon, 2008).

Furthermore, in a recent study on the wellbeing of school facilities to determine to what degree schools have healthy, physical environments, one third of the reporting districtsaffecting about 14 million students-reported school buildings in need of extensive repair or outright replacement (Jones, Brener, \& McManus, 2003). Also, nearly half of the schools reported unsatisfactory conditions such as heating, lighting, and ventilation issues. Urban schools with high minority and lowincome students had the greatest percentage of these problems. However, an important finding in the study noted that many urban districts have placed a high priority in changing or replacing these types of facilities and thus, improving student achievement.

\section{Parent Choice, Voice, and Power}

The degree of success for school choice in decreasing neighborhoods is dependent on how a school district structures program offerings and how receptive families of the available options are to engage them (Godwin, Leland, Baxter, \& South- 
worth, 2006). There are four structural components that are critical for a successful school choice program: 1) information, 2) transportation, 3) whether choice is voluntary or mandatory, and 4) whether the policy uses a lottery to determine spaces or utilizes a preferential process for students who meet specific criteria. Three years after implementing a mandatory choice plan, the Charlotte-Mecklenburg School District eliminated the word mandatory from the name of the choice policy. It also prevented students from choosing schools that had exceeded their enrollment capacity. Students not able to attend the schools of their choice, particularly students on free and reduced lunch, were most likely to remain in schools considered low-performing, as defined in the No Child Left Behind (NCLB) Act. The choice by parents varied depending on income. Their choices were usually based on academic achievement. By eliminating the choice obstacle for the district, it began to stress continuity and tried to prevent transfers from school to school.

Research has determined several factors that contribute to low academic achievement scores for African American students: 1) low participation of parents, 2) high poverty, 3) lack or little communication between school and families, and 4) lack of resources (Trotman, 2001). Parents are their children's first teachers and they should serve as their advocates and decision-makers, collaborating with school staff to meet their needs. Schools have taken on roles normally assumed by parents and unintentionally pushed parents away from any type of collaboration, even though research shows that the more parents are involved in their children's education, the more they achieve. The collaboration with parents needs to be meaningful and the child needs to understand everyone is helping them achieve their highest potential. The nuclear two-parent family of decades past has been replaced with single parent or blended families. Most low-income children live in single-parent families headed by women, often unemployed. If parents are employed, they are most likely working one or more minimum wage jobs that limit time with their children. Parents experience isolation from their child's school, defined as a lack of connection, which makes them feel out of place, particularly when they perceive discrimination. When this occurs parents refuse to communicate with school staff (Brandon, 2007). The role of the educator is a major factor between African American families and the education process. Unfortunately, there are educators who show a lack of respect for the ways in which parents raise their children. The lack of respect may be the result of not being prepared to work with cultures different than their own or unwillingness to learn the cultures of their students. All educators need to know that poverty does not equate to a lack of intelligence (Davis, 2006).

\section{Family-School Partnerships}

In decreasing neighborhoods it is imperative that familyschool partnerships be formed that provide a school-based action team framework that fosters parenting, communicating, volunteering, learning, decision-making, and collaborating within the community (Epstein et al., 2002). Partnerships involving civic activities, cultural opportunities, business, and health agencies should also be considered. One challenge would be to ensure equity for students and families to engage in programs and services of the community. Based on the study of several parent and community involvement models, students who have families actively involved in their education will most likely be successful in school (Lunenburg \& Irby, 2002). Barton (2004) discusses a framework for shifting how educators understand parent involvement in their children's schools. Barton asserts that parents may be of two minds about direct school engagement, supportive of their child's daily school experiences but unsure about the schools role in the community. The framework also provides parents a means to impact what happens to their children. Models of parent involvement in neighborhoods of economic stress and decline can be defined as useful in representing the range and type of activities that might be incorporated in parent involvement programs. Partnership programs that include parents and empower them to assist with their children's education have been shown to be effective in improving academic achievement and have a positive effect on parentteacher-school relationships (Barton, 2004).

\section{Methodology}

\section{Purpose of the Study}

The purpose of this study was to determine 1) individual student achievement, 2) teacher mobility rates, 3) perceptions of safety at school, and 4) student enrollment patterns, over time, in two recently renovated, same city, urban, No Child Left Behind compliant, Title I elementary school buildings located in close proximity neighborhoods one with improving the other with declining economic conditions.

\section{Student Participant Demographics}

Participants were fifth-grade students who attended renovated schools second-grade through fifth-grade in either a neighborhood with improving economic conditions or a neighborhood of declining economic conditions. In the renovated Title 1 elementary school facility in a neighborhood with improving economic conditions students gender was male $n=7$ (39\%) and female $n=11$ (61\%) while in the renovated Title 1 elementary school facility in a neighborhood with declining economic conditions students gender was male $n=9(60 \%)$ and female $n=6$ (40\%). The age range of study participants was 7 years old at the beginning of the study and 11 years old at the time of posttest data collection at both schools. Ethnicity of the students enrolled in the renovated Title 1 elementary school facility in a neighborhood with improving economic conditions was Black $n=5$ (28\%), Hispanic $n=5$ (28\%), White $n=7$ (39\%), and American Indian $n=1$ (5\%) and the ethnicity of the students enrolled in the renovated Title 1 elementary school facility in a neighborhood with declining economic conditions was Black $n=14$ (93\%) and White $n=1(7 \%)$. Sixteen out of $18(88 \%)$ of the students attending the elementary school facility in a neighborhood with economic improvement and 14 out of 15 (93\%) of the students attending the elementary school facility in a neighborhood with economic decline were eligible for participation in the free and/or reduced price lunch program.

\section{Description of Procedures}

California Achievement norm-referenced reading, math, and language Normal Curve Equivalent test scores of students attending both schools from second-grade through fifth-grade were compared to determine the impact of economic conditions on hoped for individual student achievement school renovation benefit. Climate survey results from 2007 were analyzed and 
compared to determine if there was a difference in reported teacher, student, and parent perceptions of how safe they feel in school and teacher mobility rates were analyzed from 20042007. Also analyzed were student enrollment patterns over this same time period for each of the schools.

\section{Research Design}

The two-group comparative efficacy study design is displayed in the following notation:

School $1 \mathrm{O}_{1} \mathrm{X}_{1} \mathrm{O}_{2}$

School $2 \mathrm{O}_{1} \mathrm{X}_{2} \mathrm{O}_{2}$

School \#1. Renovated same city, urban, close proximity, No Child Left Behind compliant, Title I elementary school building.

School \#2. Renovated same city, urban, close proximity, No Child Left Behind compliant, Title I elementary school building.

$\mathrm{X}_{1}=$ study independent variable, neighborhood economic circumstance, condition \#1. School located in a neighborhood with improving economic conditions.

$\mathrm{X}_{2}=$ study independent variable, neighborhood economic circumstance, condition \#2. School located in a neighborhood with declining economic conditions.

$\mathrm{O}_{1}=$ study school renovation renewal benefit pretest dependent measures. 1) Individual student achievement as measured by the California Achievement Test (CAT) Normal Curve Equivalent Scores (NCE) completed in March 2004 for secondgrade students' a) Reading Total, b) Math Total, and c) Language Total.

$\mathrm{O}_{2}=$ study school renovation renewal benefit posttest dependent measures. 1) Individual student achievement as measured by the California Achievement Test (CAT) Normal Curve Equivalent Scores (NCE) completed in March 2007 for fifthgrade students' a) Reading Total, b) Math Total, and c) Language Total. 2) School wide Climate Survey response to the statement: Students feel safe at this school, as measured in March 2007. 3) School wide stable or changing teacher mobility rates as measured by a) active, b) transferred, c) terminated, and d) retired teacher frequency categories. 4) School wide student enrollment patterns over time for each of the schools.

\section{Research Questions}

The following five research questions guided the study:

1) Do fifth-grade students attending a renovated school located in a neighborhood with improving economic conditions and fifth-grade students attending a renovated school located in a neighborhood with declining economic conditions have congruent or different second-grade pretest compared to fifth-grade posttest Reading Total, Math Total, and Language Total achievement test lose or improve score frequencies?

2) Do fifth-grade students attending a renovated school located in a with improving economic conditions and fifth-grade students attending a renovated school located in a neighborhood with declining economic conditions have congruent or different fifth-grade posttest compared to fifth-grade posttest Reading Total, Math Total, and Language Total Normal Curve Equivalent achievement test scores?

3) Do teachers, students, and parents who are teaching, attending, and participating in a renovated school located in a neighborhood with improving economic conditions and teachers, students, and parents who are teaching, attending, and participating in a renovated school located in a neighborhood with declining economic conditions report congruent or different posttest perceptions of whether, Students feel safe at this school?

4) Do teachers in a renovated school located in a neighborhood with improving economic conditions and teachers in a renovated school located in a neighborhood with declining economic conditions have congruent or different posttest mobility rates by categories for transferred out, terminated, or retired or active?

5) Does the renovated school located in a neighborhood with improving economic conditions and the renovated school located in a neighborhood with declining economic conditions have congruent or different posttest student enrollment patterns over time?

\section{Assumptions and Limitations of the Study}

The design of this study had several strong features including 1) school district leadership focused on having state-of-the-art school buildings, facilities, and programs regardless of the condition of the surrounding neighborhood's economic condition, 2) teachers with experience who are committed to urban education regardless of the condition of the surrounding neighborhoods, and 3) teachers who are assigned to their school of choice regardless of the condition of the surrounding neighborhoods. All data were uniformly collected and available through the school district's database. Finally, participating school district and University of Nebraska Medical Center/University of Nebraska at Omaha Joint Institutional Review Board for the Protection of Human Subjects approval was granted for the study before data were analyzed. However, the small sample size of the two urban schools reflecting differing neighborhood economic conditions could skew the statistical results and limit the utility and generalizability of the study findings.

\section{Results}

Research question \#1 results indicated that fifth-grade students $(n=18)$ who attended a renovated school second-grade through fifth-grade in a neighborhood with improving economic conditions compared to fifth-grade students $(n=15)$ who attended the renovated school second-grade through fifth-grade in a neighborhood of declining economic conditions had statistically greater high stakes achievement test score improvement frequencies over time, second-grade to fifth-grade, for chisquare Reading Total $X^{2}(1, N=33)=5.241, p=0.02$ and for chi-square with Yates' correction applied Math Total $X_{\text {Yates }}^{2}(1$, $N=33)=6.546, p=0.01$, but not for chi-square with Yates' correction applied Language Total $X_{\text {Yates }}^{2}(1, N=33)=1.560, p$ $=0.21$. Research question \#2 results found that posttest-posttest Normal Curve Equivalent achievement test score comparisons were statistically greater for fifth-grade students attending a renovated school in a neighborhood with improving economic conditions Reading Total $(M=51.39, S D=18.01$; Math Total $M=54.50, S D=19.01$; Language Total $M=51.94, S D=20.66$ ) compared to fifth-grade students attending a renovated school in a neighborhood with declining economic conditions (Reading Total $M=33.07, S D=11.36$; Math Total $M=31.07, S D=$ 15.99; Language Total $M=35.47, S D=10.70$ ) for all three achievement test measures where the independent $t$ test analysis for Reading Total was $t(31)=3.41, p=0.001$ (one-tailed), $d=$ 
0.760, Math Total was $t(31)=3.78, p=0.0003$ (one-tailed), $d=$ 0.850 , and Language Total was $t(31)=2.79, p=0.004$ (onetailed), $d=0.608$. Results for research questions \#1 and \#2 indicate that positive student achievement improvement frequencies and higher achievement test score values may be more likely to occur over time in a renovated urban school in a neighborhood with improving economic conditions while neighborhood declining economic conditions may trump any hoped for school renovation student achievement benefit. Research question \#3 chi-square results found that fifth-grade students attending a renovated school in a neighborhood with improving economic conditions and their teachers and parents compared to fifth-grade students attending a renovated school in a neighborhood with declining economic conditions and their teachers and parents had congruent posttest responses to the statement, Students feel safe at this school, where $X^{2}(2, N=422)=0.523, p=$ 0.76 . Equipoise in this statistical comparison represents hoped for school renovation benefit where all respondents believe students are safe regardless of the neighborhood's economic condition. Research question \#4 results posit that fifth-grade teachers staffing a renovated school in a neighborhood with improving economic conditions compared to teachers staffing a renovated school in a neighborhood with declining economic conditions had congruent posttest mobility rates by categories for transferred out, terminated, or retired or active where $X^{2}(1$, $N=131)=0.384, p=0.53$. Again, Equipoise in this statistical comparison represents hoped for school renovation benefit represented by a stable teaching force not affected by the neighborhood's economic condition. However, over the four year study, enrollment in the renovated school in the neighborhood with declining economic conditions dropped significantly from 328 students to 264 students while enrollment in the renovated school in the neighborhood with improving economic conditions remained stable with 307 students to 309 students where $X^{2}(1, N=1208)=3.753, p=0.05$.

\section{Conclusion}

Inspecting the chi-square lose and improve second-grade to fifth-grade Reading Total and Math Total frequencies and percents highlights the plausibility that neighborhood economic conditions can impact hoped for school renovation achievement benefit. Arguably reading and math are the most important indicators of student success and preparedness for academic promotion and continuing school—and even life-success. Students attending a renovated urban school in a neighborhood with improving economic conditions with higher fifth-grade compared to second-grade Reading Total scores $n=12$ (67\%) were statistically more likely than students attending a renovated urban school in a neighborhood with declining economic conditions to also have higher fifth-grade compared to second-grade Reading Total scores $n=4$ (27\%). Lower fifthgrade compared to second-grade Reading Total score comparisons for students attending a renovated urban school in a neighborhood with improving economic conditions were $n=6$ (33\%) and for students attending a renovated urban school in a neighborhood with declining economic conditions the observed frequency was a troubling $n=11$ (73\%). This pattern was also observed in the Math Total score comparisons where students attending a renovated urban school in a neighborhood with improving economic conditions with higher fifth-grade compared to second-grade Math Total scores $n=8$ (44\%) were statistically more likely than students attending a renovated urban school in a neighborhood with declining economic conditions to have higher fifth-grade compared to second-grade Math Total scores $n=0(0 \%)$. Lower fifth-grade compared to second-grade Math Total score comparisons for students attending a renovated urban school in a neighborhood with improving economic conditions were $n=10$ (56\%) and for students attending a renovated urban school in a neighborhood with declining economic conditions the observed frequency was again a troubling $n=15$ (100\%). Language Total score comparisons where students were attending a renovated urban school in a neighborhood with improving economic conditions with higher fifth-grade compared to second-grade Language Total scores $n=7$ (39\%) were not statistically more likely than students attending a renovated urban school in a neighborhood with declining economic conditions to have higher fifth-grade compared to second-grade Language Total scores $n=2(13 \%)$. Lower fifth-grade compared to second-grade Language Total score comparisons for students attending a renovated urban school in a neighborhood with improving economic conditions were $n=11$ (61\%) and for students attending a renovated urban school in a neighborhood with declining economic conditions the observed frequency was $n=13(87 \%)$. While equipoise was observed for the overall chi-square Language Total score comparisons lower fifth-grade compared to second-grade scores observed for students attending both schools, lower scores over time, account for the negative direction congruence.

Overall, California Achievement Test, Normal Curve Equivalent scores for students attending both renovated schools in neighborhoods with improving and declining economic conditions end of fifth-grade posttest scores were measured within the below average and average ranges. Students attending a renovated urban school in a neighborhood with improving economic conditions had a statistically greater mean Reading Total Normal Curve Equivalent score of 51.39 with a corresponding percentile rank of 53 and a stanine score of 5 , the middle stanine of the average range, a statistically greater mean Math Total Normal Curve Equivalent score of 54.50 with a corresponding percentile rank of 58 and a stanine score of 6 , the highest stanine of the average range, and a statistically greater mean Language Total Normal Curve Equivalent score of 51.94 with a corresponding percentile rank of 53 and a stanine score of 5 , the middle stanine of the average range compared to students attending a renovated urban school in a neighborhood with declining economic conditions had a mean Reading Total Normal Curve Equivalent score of 33.07 with a corresponding percentile rank of 21 and a stanine score of 4, the lowest stanine of the average range, a mean Math Total Normal Curve Equivalent score of 31.07 with a corresponding percentile rank of 18 and a stanine score of 3 , the highest stanine of the below average range, and a mean Language Total Normal Curve Equivalent score of 35.47 with a corresponding percentile rank of 23 and a stanine score of 4 , the lowest stanine of the average range. Although scores for students attending a renovated urban school in a neighborhood with declining economic conditions were at or near the average range, lower fifth-grade compared to second-grade scores noted in research question \#1 results represents lost potential and reduced school renovation achievement benefit for these students across time.

However, differing neighborhood economic conditions had no statistical effect on reported teacher, student, and parent perceptions of how safe they believe students are in school or 
teacher mobility rates. Equipoise for these comparisons represents school renovation benefit. The teacher mobility patterns of both schools reflect full teacher staffing, that is while teachers were transferred out, terminated, or retired new teachers were hired or transferred in to maintain an appropriate student to teacher ratio. Maintaining a teaching staff is important to the wellbeing of students, continuity of instruction, and parent and community belief that the school is a safe place central to a strong community. Equipoise found in these two research questions represents numerical good news for both schools. Even with these positive findings, however, the decreasing enrollment pattern observed over time in the renovated urban school in a neighborhood with declining economic conditions represents a loss of program viability and school enrollment renovation renewal benefit.

\section{Discussion}

Parents may want to study choice options for their children attending a school with declining achievement scores over time for the same group of children. The ability to choose what school a parent would want their child to attend must be part of a district school choice plan. While there are studies that suggest that the type of neighborhood does not greatly impact academic achievement (Thompson, 2003) the relationship between poorer more troubled neighborhoods student achievement and school enrollment patterns cannot be totally ignored. Understanding a student's neighborhood could help educators formulate better policy on what educational and life skills to teach so that enrolled students become academically successful, as well as socially, emotionally, and behaviorally successful through resilience intervention (Reid, 2007). By mitigating the negative effects of living in poverty at the individual or household level, community development and neighborhood revitalization efforts should result in creating and implementing important strategies for mediating the effects of neighborhood poverty (Reid, 2007). There are many cases where community development efforts have failed to connect low-income families to strong neighborhoods with good schools and living-wage employment. Reid (2007) further states that community development organizations are moving toward more comprehensive strategies for neighborhood revitalization that consider local needs while building leadership among local residents and organizations, and investing in both people and place based strategies to lessen the effects of poverty. The links between neighborhood poverty and schools and efforts to integrate education reform with community development opportunities are likely to do more than pursuing each of them alone, according to Warren (2005). Breaking down traditional divisions between school reform and community development to coordinate their efforts to revitalize neighborhoods has begun in many areas.

In the main, students who felt safe despite exposure to violence in their neighborhood, performed better on achievement tests (Ratner, Chiodo, Covington, Sokol, \& Ager, 2006). However, community violence has been linked to behavior problems in children from preschool through late adolescence. The results of this study are consistent with the findings of other research where greater exposure to violence was significantly related to poorer cognitive and achievement performance. Further, these results indicate the possible damage across such a wide range of cognitive skills and abilities. Children who reported feeling safe in this study stated there were positive, 'care giving' adults in their lives. They also were considered resilient for their ability to overcome personal adversity and still be successful in school (Ratner et al., 2006). Dysfunctional family behavior led to a sense of feeling less safe, in the study. Neighborhoods in economic decline may experience high rates of crime and violence. Isolation is manifested out of fear by parents when living in dangerous neighborhoods where families stay to themselves. Neighborhoods of economic stability or improvement find parents not as fearful about safety and more likely to connect to teachers, neighbors, and other families. One concern of high mobility families is that it disrupted social connections considered significant in the development of children (Pettit, 2004; Sinha, Payne, \& Cook, 2005). This results in the weakening of the foundation of success including academic achievement.

Warren (2005) asked the question, What sense does it make to try to reform urban schools while the communities around them stagnate or collapse? It is not feasible to restructure schools in isolation of the development of the surrounding community. Linking schools to the development in the communities in which they are located 1) improves the living conditions of families and the health of low-income communities, 2) creates conditions in which students are better able to learn, and 3) delivers greater resources to schools (Warren, 2005). Urban districts have many factors to contemplate when making decisions to close or maintain schools suffering decreasing enrollment due to achievement scores, especially when this occurs over time and does not seem to improve (Sinha et al., 2005). Parents need assistance in determining if they want their children to remain in such a school or be provided the choice to attend school elsewhere. The ability to move to another neighborhood where crime rates, transportation, and employment are factors to be considered is crucial (Viteritti, 2005).

Because the research school is located in a school district that is a member of the eleven school district Learning Community of Douglas and Sarpy Counties, NE, legislatively charged with reducing social and academic barriers to student achievement through open enrollment and resource equity, students may transfer through open enrollment to schools within the two county learning community where there are openings and their attendance would contribute to improving the economic diversity of the school they will attend (Nebraska State Statute 792104, Final Diversity Plan, Approved December 16, 2010). Therefore, in the research school where renovation did not result in improved student achievement and enrollment was decreasing we assert that proactively assisting families to transfer their students to a learning community school-intra home district or inter learning community district-in a more positive environment is both prudent and warranted.

\section{REFERENCES}

Ainsworth, J. W. (2002). Why does it take a village? The mediation of neighborhood effects on educational attainment. Social Forces, 8, 117-152. doi:10.1353/sof.2002.0038

Anyon, J., Sadovinik, A. R., \& Semel, S. F. (2001). Ghetto schooling: A political economy of urban educational reform. Educational Researcher, 30, 27-32.

Argon, J. (2008). 37th Annual maintenance and operation cost study: Schools. American School and University, 80, 21-28.

Arsen, D., \& Davis, T. (2006). Taj Mahals or decaying shacks: Patterns in local school capital stock and unmet capital need. Peabody Journal of Education, 81, 1-22. doi:10.1207/s15327930pje8104_1 
Barton, A. C., Drake, C., Perez, J. G., St. Louis, K., \& George, M. (2004). Ecologies of parental engagement in urban education. Educational Researcher, 33, 3-12. doi:10.3102/0013189X033004003

Baskerville, S. (2008). From welfare state to police state. The Independent Review, 12, 401-422.

Brandon, R. R. (2007). African American parents: improving connections with their child's educational environment. Intervention in School and Clinic, 43, 116-120.

Breitborde, M. (2002). Lessons learned in an urban school: Preparing teachers for the educational village. The Teacher Educator, 38, 3446. doi:10.1080/08878730209555305

Bryan, J. (2005). Fostering educational resilience and achievement in urban schools through school-family-community partnerships. Journal of Professional School Counseling, 8, 219-227.

Burke, R. W. (2002). Social and emotional education in the classroom. Kappa Delta Pi, 38, 108-111.

Burkhauser, R. V., \& Sabia, J. J. (2007). The effectiveness of minimum wage increases in reducing poverty: Past, present and future. Economic Policy, 25, 262-281.

Crew, R. (2007). Only connect: The way to save our schools. New York, NY: Farrar, Straus and Giroux.

Crowley, S. (2003). The affordable housing crisis: Residential mobility of poor families and school mobility of poor children. Journal of Negro Education, 72, 22-38. doi:10.2307/3211288

Davis, B. (2006). How to teach students who don't look like you: Culturally relevant teaching strategies. Thousand Oaks, CA: Corwin Press.

Earls, F. (2000). Urban poverty: Scientific and ethical considerations. Annals of the American Academy of Political and Social Science, 572, 53-65. doi:10.1177/0002716200572001009

Epstein, J., Sanders, M., Simon, B. S., Salinas, K. C., Jansorn, N. R., \& Van Voorhis, F. L. (2002). School, Family, and Community Partnerships: Your Handbook for Action (2nd ed.). Thousand Oaks, CA: Corwin Press.

Frankenberg, E., \& Lee, C. (2002). Race in American public schools: Rapidly resegregating school districts. Cambridge, MA: Civil Rights Project, Harvard University.

Gehrke, R. S. (2005). Poor schools, poor students, successful teachers. Kappa Delta Pi Record, 42, 14-17.

Godwin, K. R., Leland, S. M., Baxter, A. D, \& Southworth, S. (2006). Sinking swann: Public school choice and the resegregation of Charlotte Public Schools. Review Policy Research, 23, 983-997. doi:10.1111/j.1541-1338.2006.00246.x

Gordon, P., \& Richardson, H. W. (2001). The sprawl debate: Let markets plan. Publius, 31, 131-149.

doi:10.1093/oxfordjournals.pubjof.a004901

Green, G. (2007). Bullying: A concern for survival. Education, 128, 333-336.

Haley-Lock, A., \& Shah, M. F. (2007). Protecting vulnerable workers: How public policy and private employers shape the contemporary low-wage work experience. Families in Society, 88, 485-495.

Hall, P. S. (2005). Bullying and the teacher. Delta Kappa Gamma Bulletin, 72, 45-49.

Haws, M. A., \& Tennille, S. (2005). Addressing bullying in school: What can educators and parents do to create a safe environment. International Journal of Humanities and Peace, 21, 14-18.

Hirsch, E. J., Lewis-Palmer, T., Sugai, G., \& Schnacker, (2004). Using school bus discipline referral data in decision-making: Two case studies. Preventing School Failure, 48, 4-9. doi:10.3200/PSFL.48.4.4-9

Jacob, B. A. (2004). Public housing, housing vouchers, and student achievement: Evidence from public housing demolition in Chicago. American Economics Review, 94, 16-19. doi:10.1257/000282804322970788

Jones, S. E., Brener, N. D., \& McManus, T. (2003). Prevalence of school policies, programs, and facilities that promote a healthy physical school environment. American Journal of Public Health, 93, 1570-1575. doi:10.2105/AJPH.93.9.1570

Kinlock, T. W., Battejes, R. J., \& Gordon, M. S. (2004). Factors associated with criminal severity among adolescents ending substance abuse treatment. Journal of Drug Issues, 34, 293-318. doi:10.1177/002204260403400203

Kozol, J. (1991). Savage inequalities. New York, NY: Crown Publishing.

Kozol, J. (2005). The shame of the nation. New York, NY: Crown Publishing.

Lawhon, L. L. (2003). Planners' perceptions of their role in socially responsive neighborhood design. Journal of Architectural and Planning Research, 20, 153-163.

Lunenburg, F., \& Irby, B. J. (2002). Parent involvement: A key to student achievement. Huntsville, TX: Sam Houston State University.

McLean, R. (2003). Seven red herrings: The opposition to closure of aging urban schools. Clearing House, 76, 140-145. doi:10.1080/00098650309601990

Meredith, J. R. (2003). Sprawl and the new urbanist isolution. Virginia Law Review, 89, 447-503. doi:10.2307/3202437

National Education Association (2004). Culture abilities resilience effort: Strategies for closing the achievement gaps. Washington DC: National Education Association.

Nebraska State Statute 79-2104 (2010).

Nichols, L., \& Gault, B. (2003). The implication of welfare reform for housing and school instability. Journal of Negro Education, 72, 104116. doi:10.2307/3211294

Omaha Public Schools (2004). Safe and secure learning environments: Best practices of the Omaha Public Schools to support the social, emotional, and behavioral success of all students: Omaha Public Schools.

Pettit, B. (2004). Moving and children's social connections: Neighborhood context and the consequences of moving for low-income families. Sociological Forum, 19, 61-79. doi:10.1023/B:SOFO.0000031983.93817.ff

Picus, L. O., Marion, S. F., Calvo, N., \& Glenn, W. J. (2005). Understanding the relationship between student achievement and the quality of educational facilities: Evidence from Wyoming. Peabody Journal of Education, 80, 71-95. doi:10.1207/s15327930pje8003_5

Plybon, L. E., \& Kliewer, W. (2001). Neighborhood types and externalizing behavior in urban school-age children: Tests of direct, mediated, and moderated effects. Journal of Child and Family Studies, 10, 419-437. doi:10.1023/A:1016781611114

Polakow, V., \& Pettigrew, S. (2006). Radical possibilities. Educational Studies, 40, 322-327.

Rankin, B. H., \& Quane, J. M. (2000). Neighborhood poverty and the social isolation of inner-city African American families. Social Forces, 79, 139-154. doi:10.1093/sf/79.1.139

Ratner, H. H., Chiodo, C., Covington, C., Sokol, R. J., \& Ager, J. (2006). Violence exposure, academic performance, and children's perception of safety: Evidence of protective effects. Merrill-Palmer Quarterly, 52, 264-287. doi:10.1353/mpq.2006.0017

Reid, C. (2007). Back to school: Prioritizing education in community development efforts. Community Investments, Fall, 3-30.

Secombe, K. (2002). "Beating the odds” versus “changing the odds": Poverty, resilience, and family policy. Journal of Marriage and the Family, 64, 384-394. doi:10.1111/j.1741-3737.2002.00384.x

Sinha, V., Payne, M. R., \& Cook, T. D. (2005). A multidimensional approach to understanding neighborhood schools and their impact. Urban Education, 40, 627-662. doi:10.1177/0042085905281393

Storch, E. A., Krain, A. L., Kovacs, A. H., \& Barlas, M. E. (2002). The relationships of communication beliefs and abilities to peer victimization in elementary school children. Child Study Journal, 32, 231240.

Taylor, J. (2005). Achieving excellence in urban schools: Pitfall, pratfalls, and evolving opportunities. Achieving Excellence in Schools, 56, 259-283.

Thompson, G. L. (2003). No parent left behind-Strengthening ties between educators and African American parents/guardians. Urban Review, 35, 7-23. doi:10.1023/A:1022589405679

Tolnay, S. E., Crowder, K. D., \& Adelman, R. M. (2000). “Narrow and filthy alleys of the city"? The residential settlement patterns of black southern migrants to the north. Social Forces, 78, 989-1015. doi: $10.2307 / 3005939$

Towns, D. P., Cole-Henderson, B., \& Serpell, Z. (2000). The journey to urban school success: Going the extra mile. The Journal of Negro 


\section{L. GRICE ET AL.}

Education, 70, 4-18.

Trotman, M. F. (2001). Involving the African American parent: Recommendations to increase the level of parent involvement within African American families. Journal of Negro Education, 70, 275285. doi:10.2307/3211280

Varady, D. P., Raffel, J. A., Sweeney, S., \& Denson, L. (2005). Attracting middle-income families in the Hope VI public housing revitalization program. Journal of Urban Affairs, 27, 149-164.

doi:10.1111/j.0735-2166.2005.00229.x

Viteritti, J. P. (2005). School choice: How an abstract idea became a reality. In D. Ravitch (Ed.), Brookings Papers on Educational Policy (pp. 137-173). Washington DC: Brookings Institute Press.

Warren, M. R. (2005). Communities and schools: A new view of urban education reform. Harvard Educational Review, 75, 133-173.

Weisberg, R. P., \& O’Brien, M. U. (2004). What works in school-based social and emotional learning programs for positive youth development. The Annals of the American Academy of Political and Social Sciences, 591, 86-97. doi:10.1177/0002716203260093 